\title{
Esterilización del Instrumento de Laparoscopia, con rayos ultravioleta.
}

\author{
Dr. SAULO MUÑOZ DELGADO
}

Entre los problemas de orden técnico que han surgido en los Programas de Planificación, se cuentan las dificultades tanto en la conservación como en la esterilización de los aparatos de endoscopia.

La parte óptica de los Laparoscopios es uno de los puntos vulnerables y que con más frecuencia requiere cambios de sus partes.

Esto se debe principalmente a que las sustancias que se emplean para la esterilización corroen el material que obtura los lentes permitiendo la entrada del líquido dentro de la parte óptica.

Por otra parte si se trata de evitar la esterilización con líquidos mediante el uso de tabletas o sustancias que produzcan vapores que esterilizan el medio, se aumenta el tiempo requerido para el procedimiento por lo menos en una hora lo cual lo hace poco práctico para la cirugía en programas de $\mathrm{Pla}^{-}$ nificación Familiar en los cuales se necesita reducir al mínimo el tiempo de este proceso.

Los problemas anotados señalaban la necesidad de buscar un sistema seguro, y rápido y que al mismo tiempo no dañe la parte óptica del aparato endoscópico.

La radiación ultravioleta de onda corta que pertenece a los rayos invisibles de la luz solar y que aparentemente no produce ningún efecto dañino al organismo humano, ha probado ser un método efectivo en la destrucción de todos los gérmenes patógenos o en estado espurulante, así como las bacterias, los fermentos y los virus.

La destrucción de estos microorganismos se produce al ser alcanzada por la radiación ultravioleta de $254 \mathrm{~nm}$. Se realiza por la absorción de la energía en los cuerpos protéicos que conduce a la destrucción de la célula. La dosis se define multiplicando la energía que choca contra una superficie por el

* PROFESOR

AREA MATERNO INFANTIL

FACULTAD DE MEDICINA

UNIVERSIDAD LIBRE DE CALI

*DIRECTOR

PROFAMILIA CALI tiempo de actuación, es decir:

$$
\frac{\text { energía } \mathrm{x} \text { tiempo }}{\text { superficie }} \frac{\mathrm{W} \times \mathrm{seg}}{\mathrm{cm}^{2}}
$$

La eficacia de un radiador se caracteriza por un rendimiento de dosis, es decir, por la energía radiada sobre una determinada superficie. El presente trabajo describe la primera experiencia de aplicar a la práctica de la esterilización del instrumental de endoscopia el conocimiento teórico sobre la capacidad destructiva de gérmenes de los rayos ultravioleta.

\section{MATERIAL Y METODOS}

A- Se probó la eficacia del esterilizador de rayos ultravioleta "Ultramatic de Luxe 471 Inelmec patente número 147574.

Se contaminaron dos cajas de Petri en la siguiente proporción de cada microorganismo: $100-10.000$ y $1.000 .000 \mathrm{ml}$.

Se colocaron dentro del esterilizador por 60 minutos una caja de Petri tapada y otra destapada; luego se les agregó medio cultivo $y_{1}$ se incubaron por 72 horas junto con dos cajas también contaminadas, pero no expuestas (o sea controles positivos), de cada microorganismo. La temperatura interior del aparato fue de 50 a $55^{\circ} \mathrm{C}$ durante el tiempo que estuvo en servicio.

B- Para este estudio se tomaron los laparoscopios y se contaminaron inicialmente en su superficie y luego en su parte interior con cultivos de estafilococo, de 1.000 .000 $\mathrm{m} / \mathrm{L}$ coli y Klebsiela, se expusieron a los rayos ultravioleta por 60 minutos y luego se agregaron medios de cultivo. Se tuvieron controles para verificar la positividad de los cultivos. Los medios usados fueron:

EUGENAR - AGAR - NUTRIENTE - CALDO DE TRYPTICASE - TIOGLICOLATO FLUIDO.

C- Se emplearon durante los seis meses los laparoscopios esterilizados por el método anteriormente descrito en pacientes de Profamilia Cali observando las complicaciones 
El Espectro Electrongyttélico
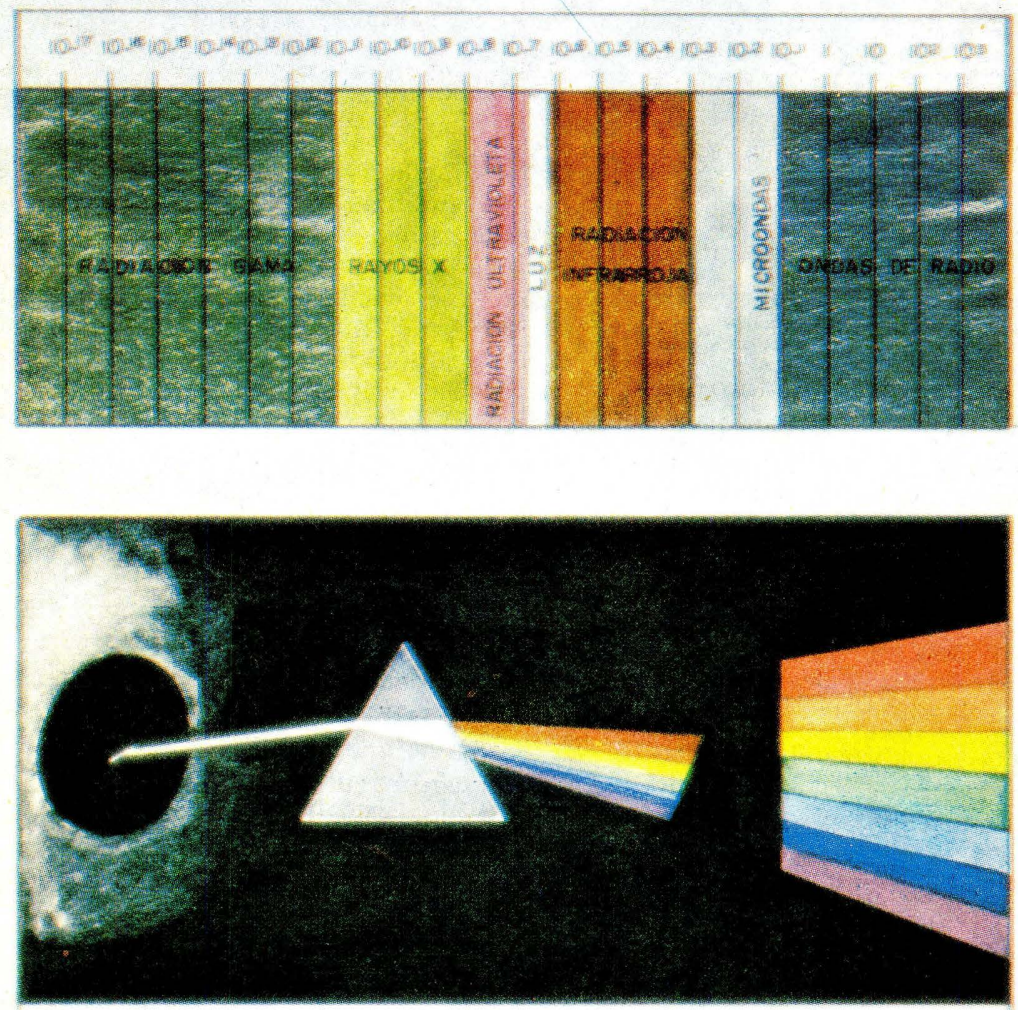

Espectro Confisto

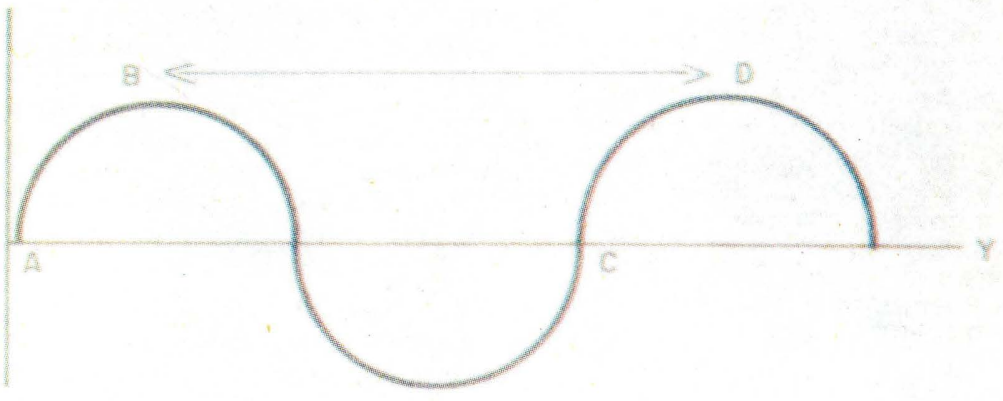

Longitad de ondic

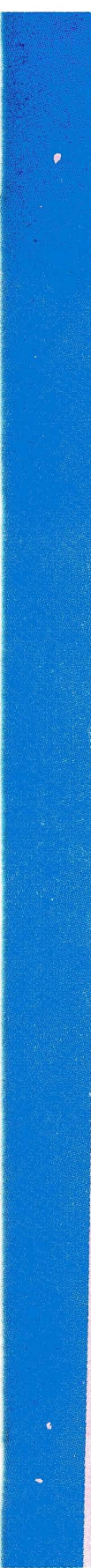




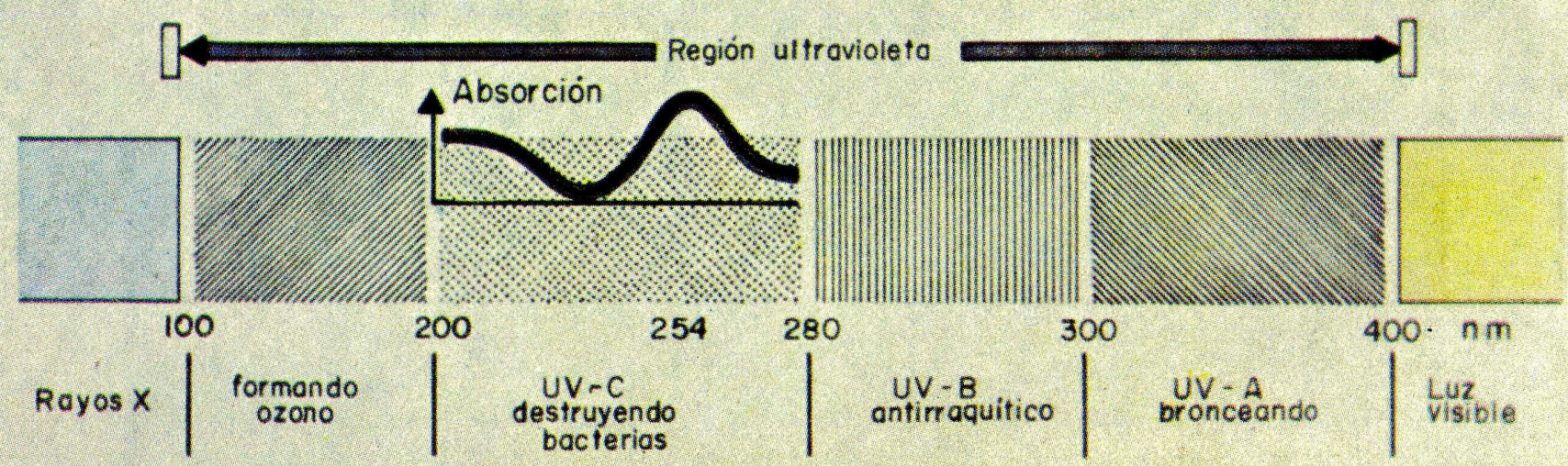

Espectro de la radiación ultravioleta con la curva de absorción esbozada 

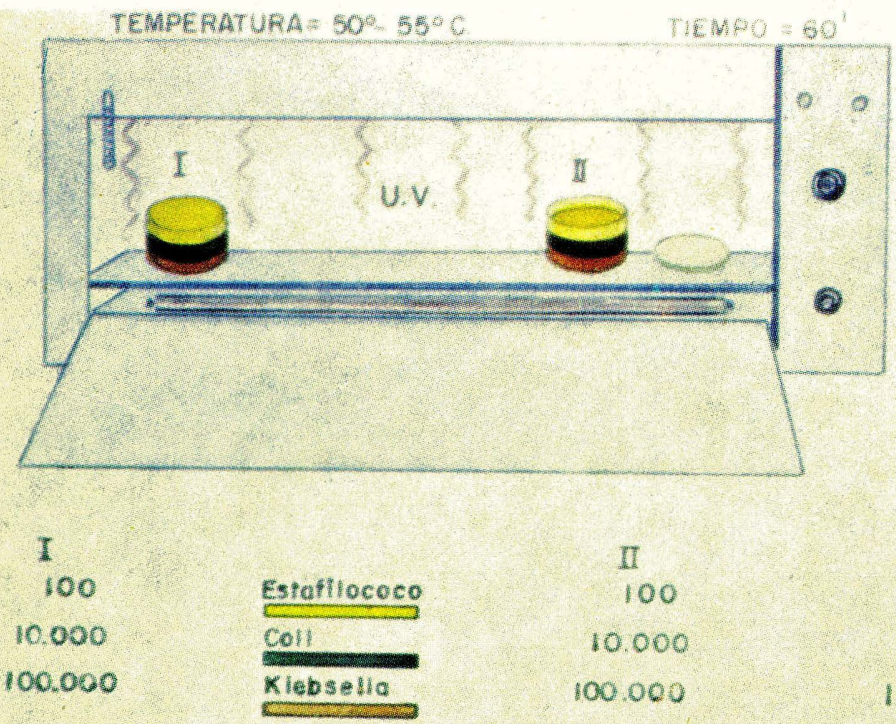

$1-A$

Soulo Muñoz Delgodo

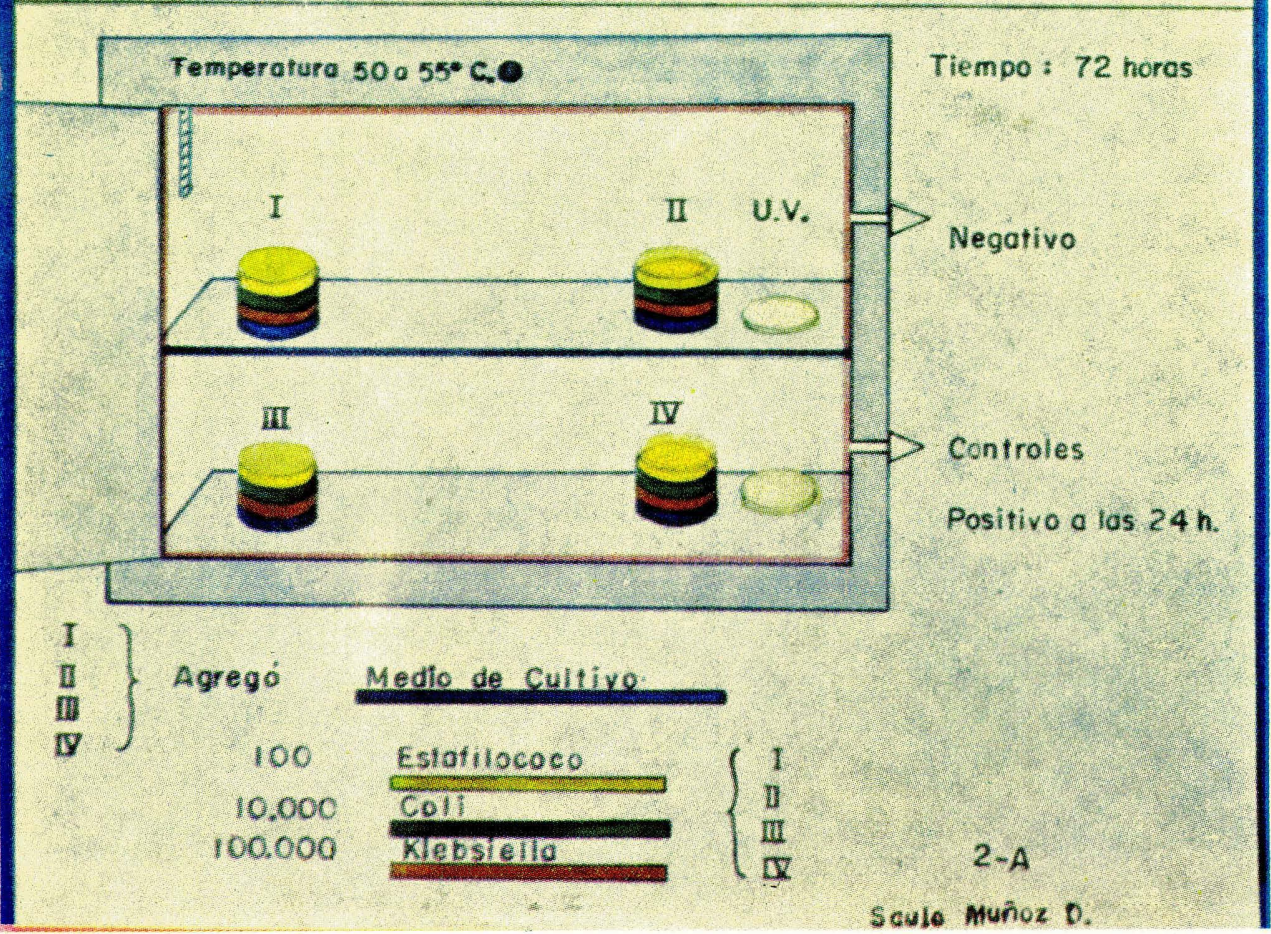




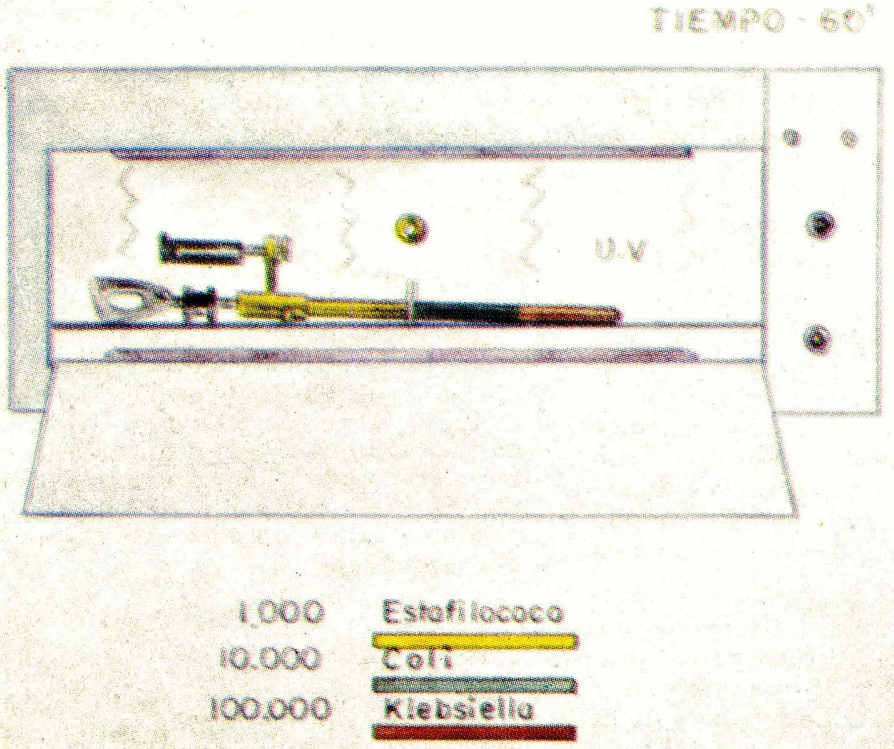

Soule Mufor Celgsue

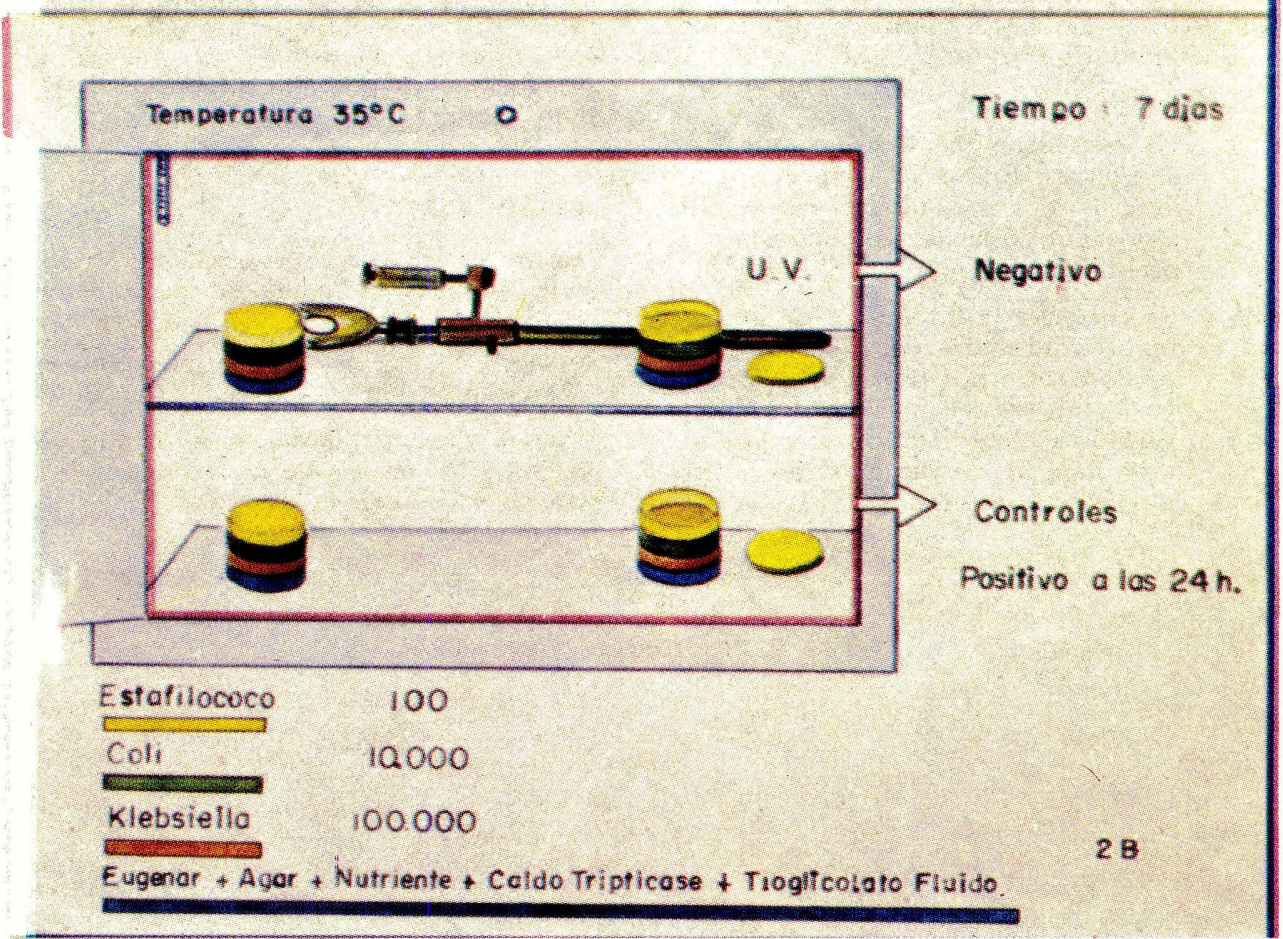


que se presentaron tanto en el postoperatorio inmediato como en el tardío.

\section{RESULTADOS}

A- Todas las cajas expuestas a esterilización de rayos ultravioleta presentaron resultados negativos para crecimiento de colonias.

En los controles los resultados fueron positivos observándose crecimiento abundante a las 24 horas.

B- El resultado para los cultivos con muestras obtenidas de los laparoscopios contaminados por estafilococos (después de incubación por 7 días a $35^{\circ} \mathrm{C}$.), fue negativo después de la exposición a rayos ultravioleta por 60 minutos. Los controles dieron crecimiento de colonias a las 24 horas. La temperatura alcanzada durante la exposición fue de $55^{\circ} \mathrm{C}$.

C- Los pacientes sometidos a laparoscopia con el instrumento esterilizado en la forma anteriormente indicada no presentaron morbilidad infecciosa atribuible a la falta de esterilización.

El número de pacientes a los cuales se practicó el procedimiento durante seis meses alcanzó un total de 1.234 mujeres usuarias de los servicios de Profamilia, Cali.

\section{CONCLUSIONES}

1o. La esterilización por 60 minutos del equipo de Endoscopia en el aparato descrito de rayos ultravioleta es efectiva según lo sustentan los resultados preliminares.

2o. Se conserva la integridad de los elementos del laparoscopio susceptibles de corrosión por líquidos antisépticos, y en los seis meses que se ha $u-$ tilizado el esterilizador de rayos ultravioleta el instrumento no sufrió ningún desperfecto. 3o. Las experiencias en humanos han demostrado la ausencia de morbilidad infecciosa atribuible a este procedimiento de esterilización del equipo, y por lo tanto cumple normas de seguridad completament, satisfactorias.

\section{RESUMEN}

La utilización de rayos ultravioleta en la esterilización de instrumentos de laparoscopia ha dado resultados óptimos, pues en un servicio abigarrado de pacientes como la consulta de planificación familiar de Profamilia en la ciudad de Cali (Colombia), se demostró como un medio confiable, de acuerdo con los estudios bacteriológicos practicados y la ausencia de posibles infecciones en pacientes tratadas. (1. 234 mujeres).

\section{SUMMARY}

The use of ultraviolet rays in the sterilization of laparoscopy instruments has yielded excellent results, in the widelyused family planning service of Profamilia in the city of Cali, Colombia, it was proven to be a reliable means of sterilizing according to bacteriological studies and the absence of possible infections in treated patients (1.234 women).

\section{BIBLIOGRAFIA}

-Mijares - Grau J. A. "Desinfección y Esterilización". Asepcia en Cirugía, Ed. Barcelona Toray 1974.

Esterilización del aire con radiadores Ultravioleta Sterisol

-Cabrera Aurelio, Informe Personal. Ensayo de esterilización Ultramatic de Luxe Inelmec pa tente número 147574 . 